\title{
Effects of Palm Kernel Shell on the Microstructure and Mechanical Properties of Recycled Polyethylene/Palm Kernel Shell Particulate Composites
}

\author{
Agunsoye J. Olumuyiwa*, Talabi S. Isaac, Obe A. Adewunmi, Adamson I. Ololade \\ Department of Metallurgical and Materials Engineering, University of Lagos, Lagos, Nigeria \\ Email: jagunsoye@unilag.edu.ng
}

Received May 16, 2012; revised June 30, 2012; accepted July 20, 2012

\begin{abstract}
The effect of palm kernel shell on the microstructure and mechanical properties of recycled polyethylene (RLDPE) reinforced with palm kernel shell particulate composite was evaluated to assess the possibility of using it as a new material for engineering applications. The composites were produced by compounding and compressive moulding technique by varying the Palm kernel shell particle from 5 - 25 vol\% with particles size of 150, 300 and $400 \mu \mathrm{m}$. The microstructure (SEM/EDS) and the mechanical properties of the composites were investigated. The hardness of the composite increases with increase in palm kernel shell content and the tensile strength of the composite increased to optimum of 5 vol\%. Scanning electron Microscopy (SEM) of the composites surfaces indicates fairly interfacial interaction between the palm kernel shell particles and the RLDPE matrix. The composites produced with $150 \mu \mathrm{m}$ particle size have the best properties of the entire grade. Hence this grade can be use for interior applications such as car seat, dash board, and car interior for decorative purposes or other interior parts of automobile where high strength is not considered a critical requirement.
\end{abstract}

Keywords: Recycled Polyethylene; Palm Kernel Shell; Microstructure and Properties

\section{Introduction}

Composites are materials that comprise strong load carrying material (known as reinforcement) imbedded in weaker material (known as matrix). Reinforcement provides strength and rigidity, helping to support structural load. In recent years, due to growing environmental awareness, agro-fillers (agro-based waste) have been increasingly used as reinforcing fillers in thermoplastic composite materials [1-2].

Natural fibers, as reinforcement, have recently attracted the attention of researchers because of their advantages over other established materials. They are environmentally friendly, fully biodegradable, abundantly available, renewable and cheap and have low density. Natural fiber composites are used in place of glass mostly in nonstructural applications. A number of automotive components previously made with glass fiber composites are now being manufactured using environmentally friendly composites [2]. This may be attributed to low-weight ratio of the composites.

Thousands of tons of different crops are produced but most of their wastes do not have any useful utilization.

\footnotetext{
"Corresponding author.
}

Agricultural wastes include wheat husk, rice husk, and their straw, hemp fiber and shells of various dry fruits Mechanical properties of plant fibers are much lower when compared to those of the most widely used competing reinforcing glass fibers. However, because of their low density, the specific properties (property-to-density ratio), strength, and stiffness of plant fibers are comparable to the values of glass fibers [3-4]. Plant fibers are light compared to glass, carbon and aramid fibers. The biodegradability of plant fibers can contribute to a healthy ecosystem while their low cost and high performance fulfill the economic interest of industry.

Oil palm fibers have been extensively studied for the production of various composites, such as thermoplastic composites, particleboard, medium density fireboard polymer impregnated oil palm trunk and other thermoset composites [3]. For thermoplastics composites, empty fruit bunch and oil palm frond has been the focus of many researchers. This is due mainly to cost, availability and properties. Oil Palm Fibers has been discovered to introduce better wear characteristics to polyester compared to glass fiber while it showed lower mechanical property than Chopped strand mat Glass fiber Reinforced Polyester [4-6]. Treating Oil Palm Fibers has significant 
effect on the wear and frictional performance of Oil Palm Fiber Reinforced Polyesters composites. It enhanced the wear properties of polyester by about 35 to 52 and 65 to 75 percent in the case of the pin-on-disc and block-onring techniques respectively. An investigation was conducted to enhance and predict the modulus of elasticity (MOE) of palm kernel shell concrete (PKSC), a highest value of $11 \mathrm{kN} / \mathrm{mm}^{2}$ was recorded and an equation which predict the MOE close to the experimental values was also developed [1].

The disposable component of harvested agricultural product (palm kernel) and pelletized pure-water nylon are becoming increasingly problematic in Nigeria, littering the rural and urban areas of the country, and constituting a serious threat to environmental health of the nation. The purpose of the research is to explore the potential of using palm kernel shell (powder) as reinforcement in polymer matrix composite for the development of new engineering material for the car interior.

\section{Experimental Procedure}

The palm kernel shell was dried and grinded into powder using a pulverizing machine, the powder was sieved in accordance with BS1377:1990 standard [7-8]. The recycled polyethylene was sun-dried and shredded in a plastic crusher machine. The palm kernel shell powder and the grinded pelletized recycled polyethylene were blend together using a two-roll rheomixer at $165^{\circ} \mathrm{C}$ and a rotor speed of $60 \mathrm{rpm}$. The percentage of the kernel shell particles in the matrix was varied from 5\% - 25\% and five samples each were compacted using $150 \mu \mathrm{m}, 300 \mu \mathrm{m}$, $400 \mu \mathrm{m}$. Compression of the composites was carried out in a Wabash V200 hot press for 5 minutes under controlled pressure 30 tons at $175^{\circ} \mathrm{C}$. Each of the samples was cooled to room temperature under pressure before it was removed from the press. Prior to testing, all samples were conditioned for 72 hours at a temperature of $23^{\circ} \mathrm{C} \pm$ $2^{\circ} \mathrm{C}$ and a relative humidity of $50 \% \pm 5 \%$.

The hardness property of samples produced was determined using Rockwell hardness tester on scale B with a $1.56 \mathrm{~mm}$ steel ball under a minor load of $10 \mathrm{~kg}$, major load of $100 \mathrm{~kg}$, and a standard block of 101.2 HRB.

A charpy impact machine was used to determine the impact energy of the samples. Tensile test of the composites was carried out using the Hounsfield tensometer and the scanning electron microscope (SEM) JEOL JSM6480LV were used to identify the surface morphology of the composite samples. The rate of water absorption of the samples was determined by initially weighed dried samples and placed in a beaker with water and reweighed at an interval of 24 hrs for $168 \mathrm{hrs}$. The water absorption rate was then determined using Equation (1) [9].

$$
\text { \%weight gained }=\frac{\text { final weight }- \text { initial weight }}{\text { initial weight }} \times 100
$$

\section{Result and Discussion}

The morphology of the developed composites are shown in Plates 1-7. From the morphology it, can be seen from the Scanning Electron Microscope results that homogeneity between the kernel shell particles and the matrix decreases with increase in the kernel shell particles content. The mwicrostructure clearly shows that when the kernel shells particle was added to the recycled polyethylene (RLDPE) morphological change in the structure take place. The microstructure of the RLDPE matrix reveals chain of lamellae and interlammeller amorphous structure with linear boundaries between adjacent spherulites boundaries (see Plate 1). From the EDS spectrum it can be clearly see that the functional group of the RLDPE were revealed.

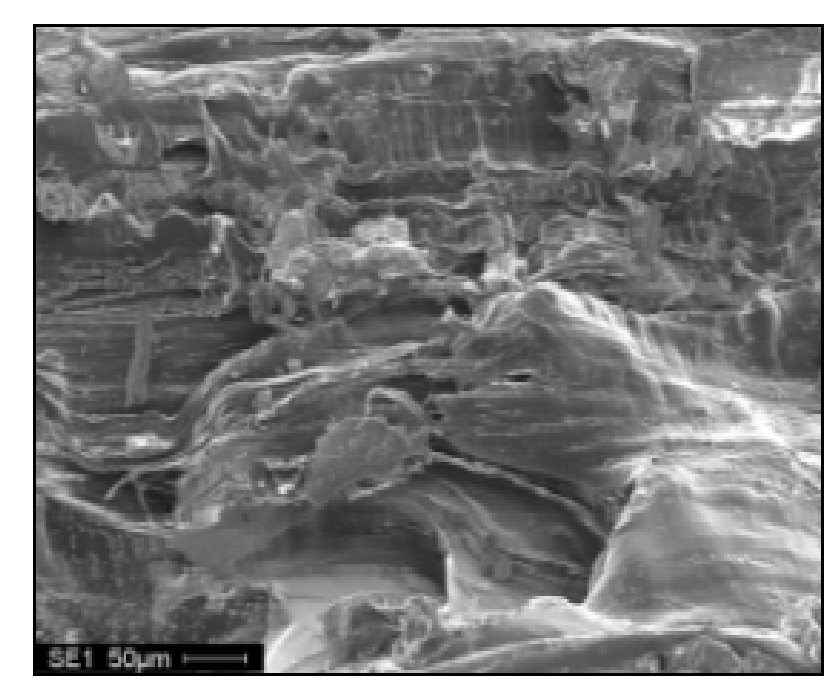

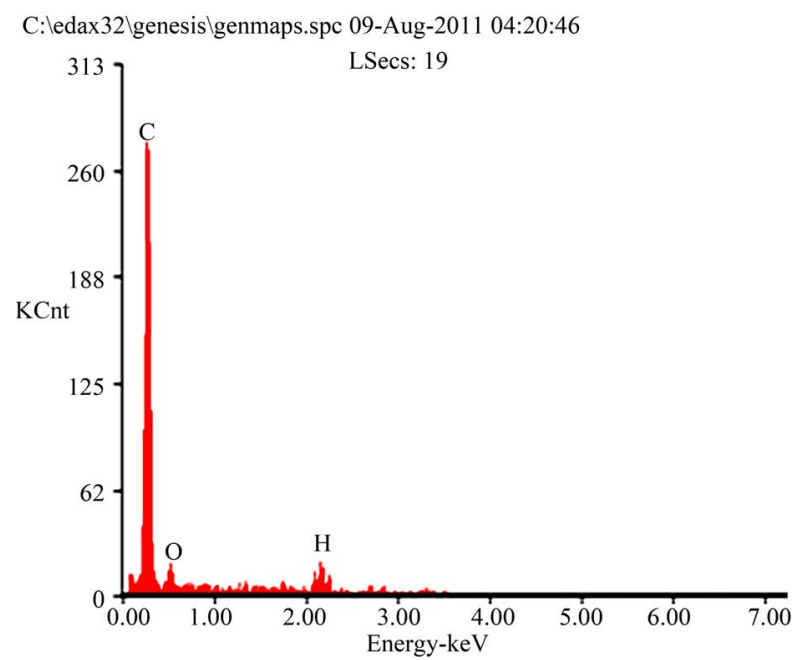

Plate 1. EDS/SEM morphology of the recycled polyethylene. 

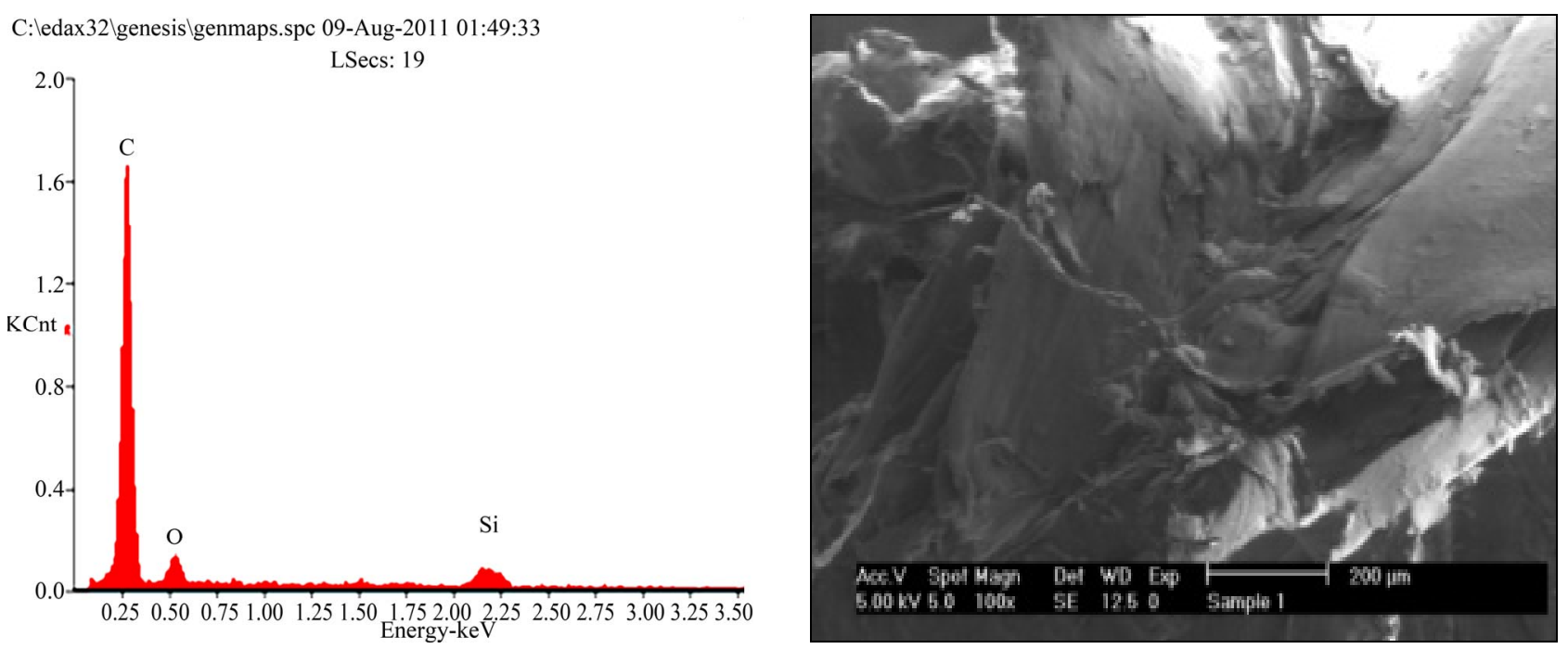

Plate 2. EDS/SEM morphology of the recycled polyethylene reinforced with $10 \mathrm{vol} \%$ at $150 \mu \mathrm{m}$ size.
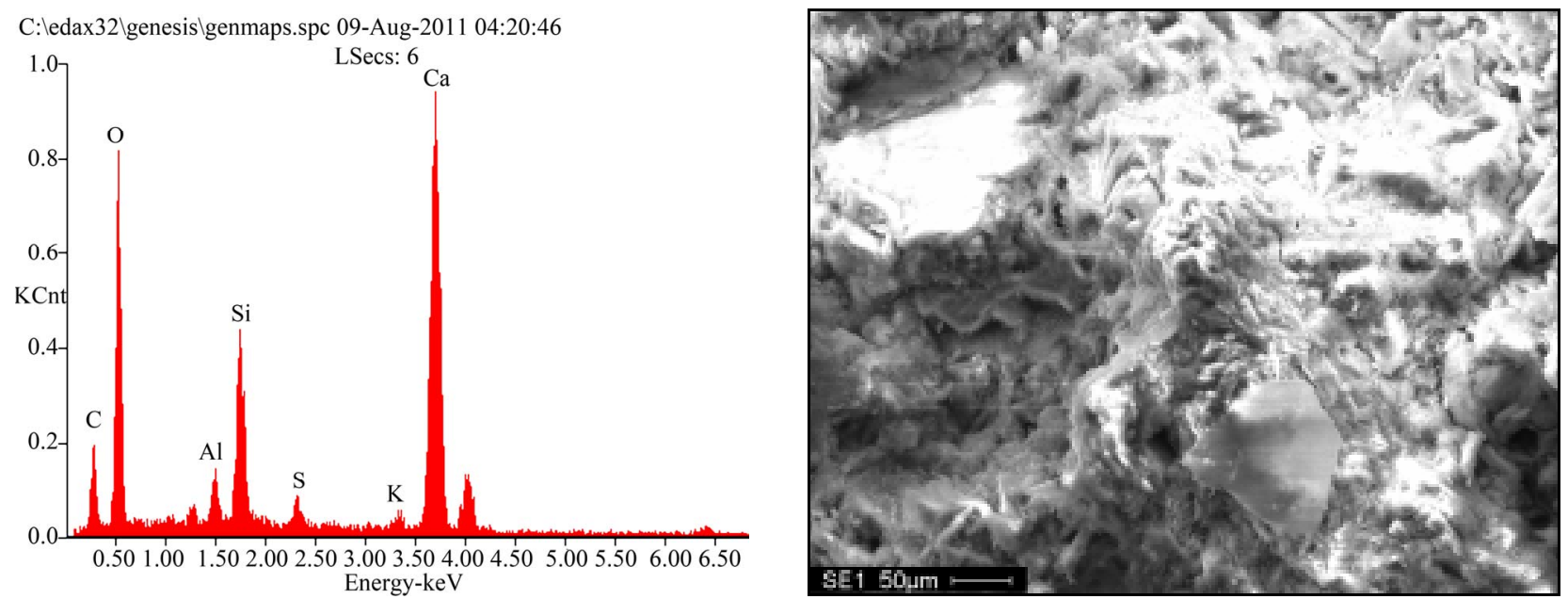

Plate 3. EDS/SEM morphology of the recycled polyethylene reinforced with $25 \mathrm{vol} \%, 150 \mu \mathrm{m}$ size.
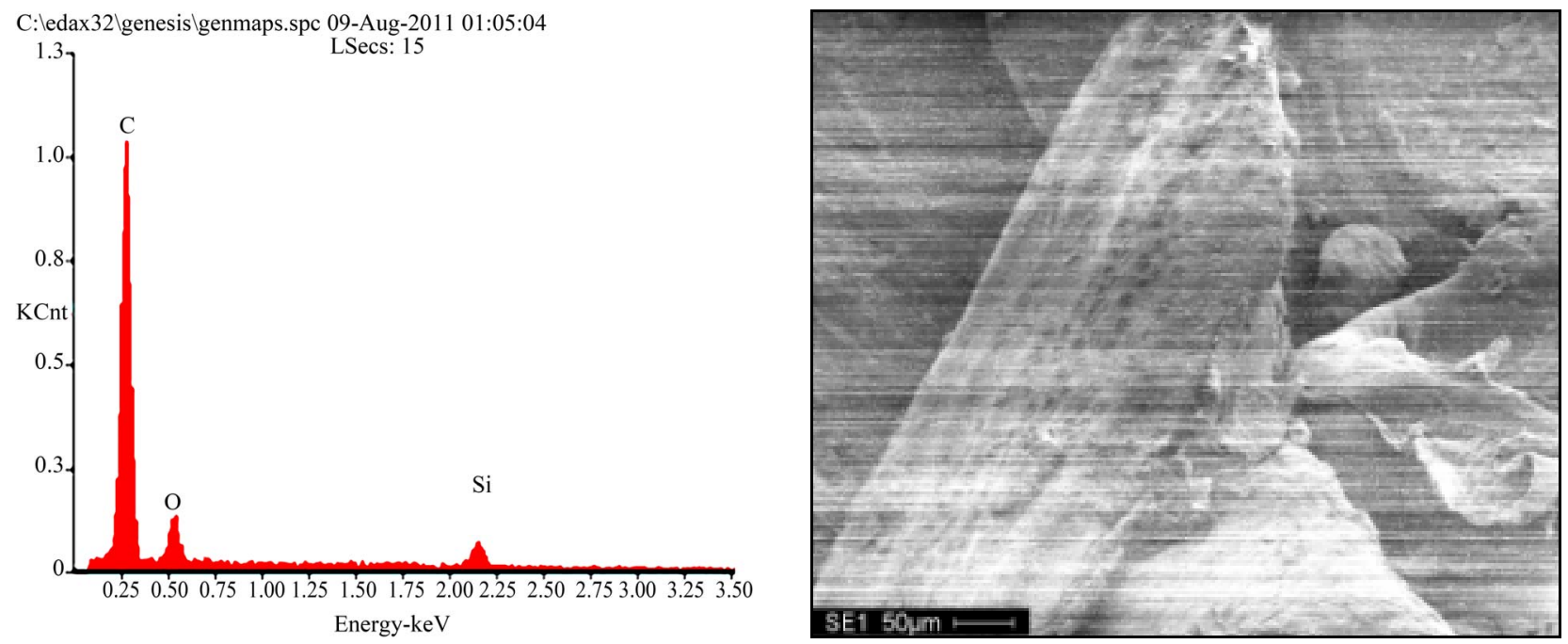

Plate 4. EDS/SEM morphology of the recycled polyethylene reinforced with $5 \mathrm{vol} \%, 300 \mu \mathrm{m}$ size. 

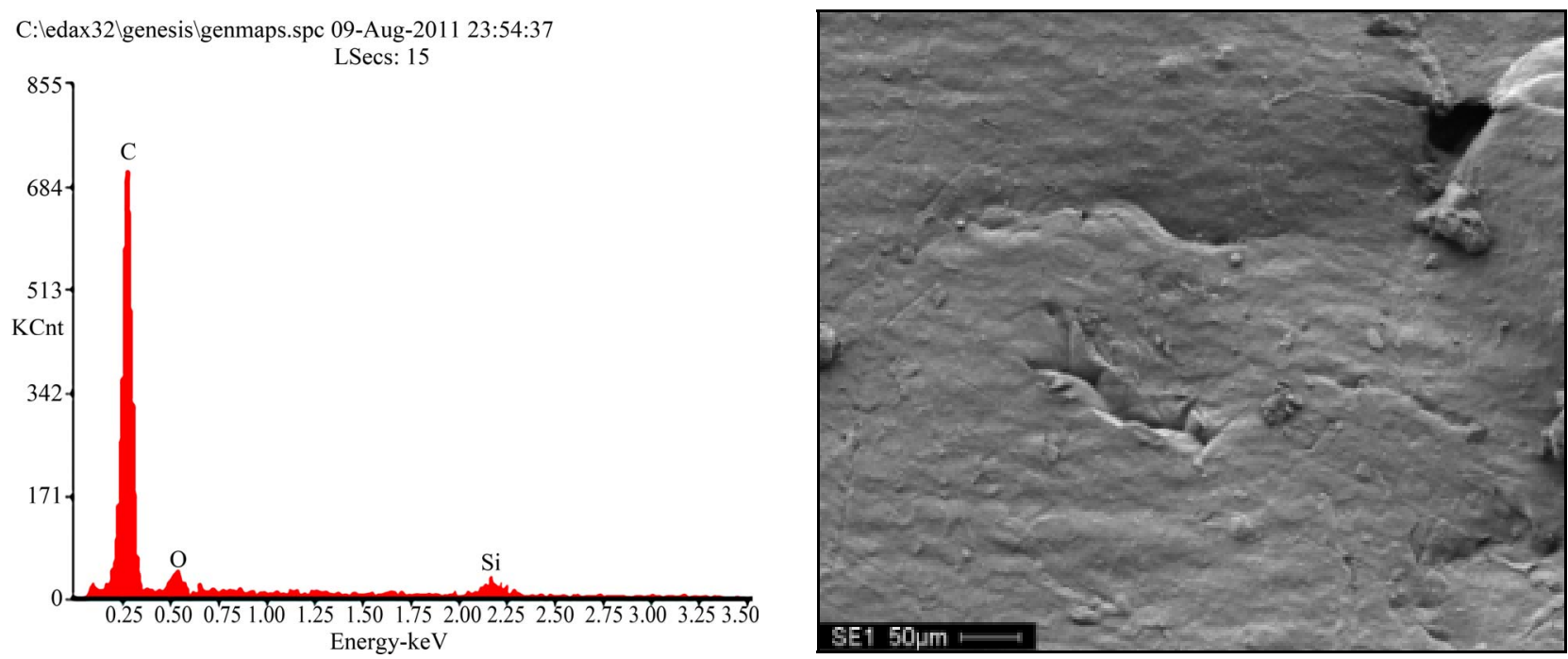

Plate 5. EDS/SEM morphology of the recycled polyethylene reinforced with $20 \mathrm{vol} \%, 300 \mu \mathrm{m}$ size.
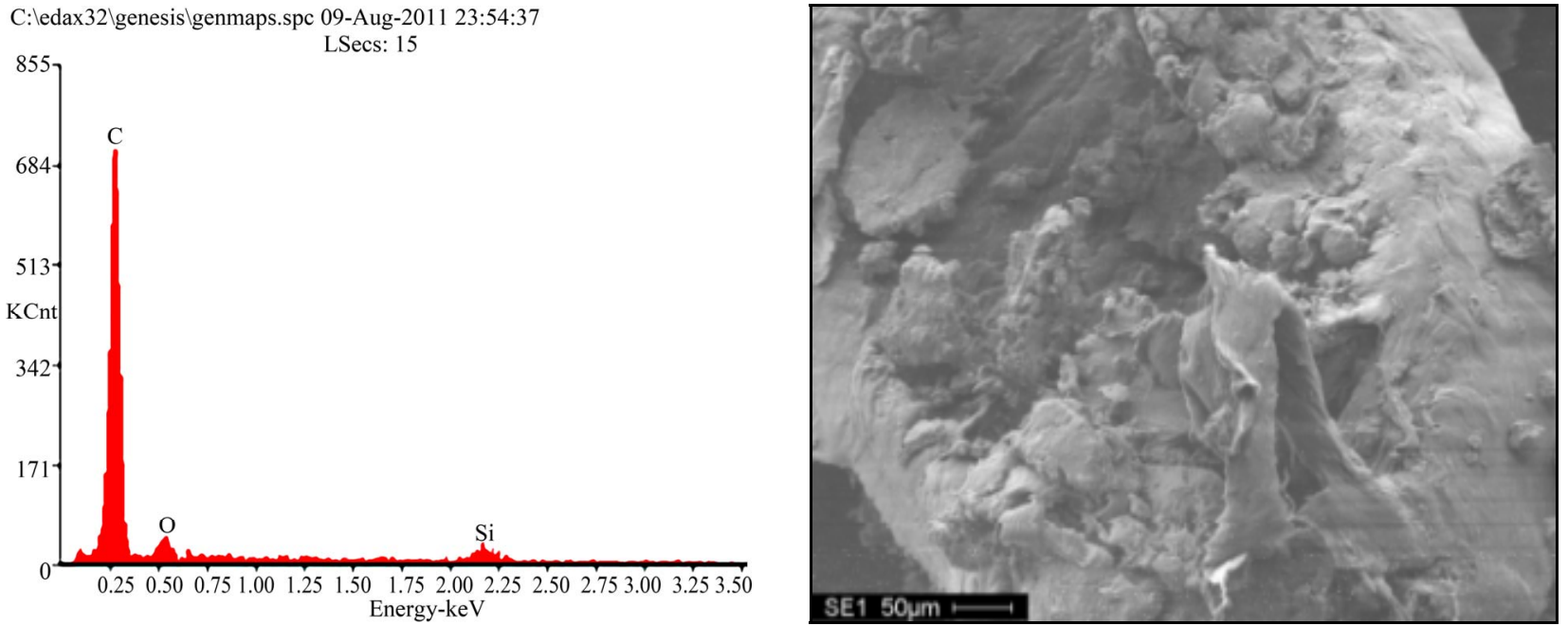

Plate 6. EDS/SEM morphology of the recycled polyethylene reinforced with $15 \mathrm{vol} \%, 400 \mu \mathrm{m}$ size.
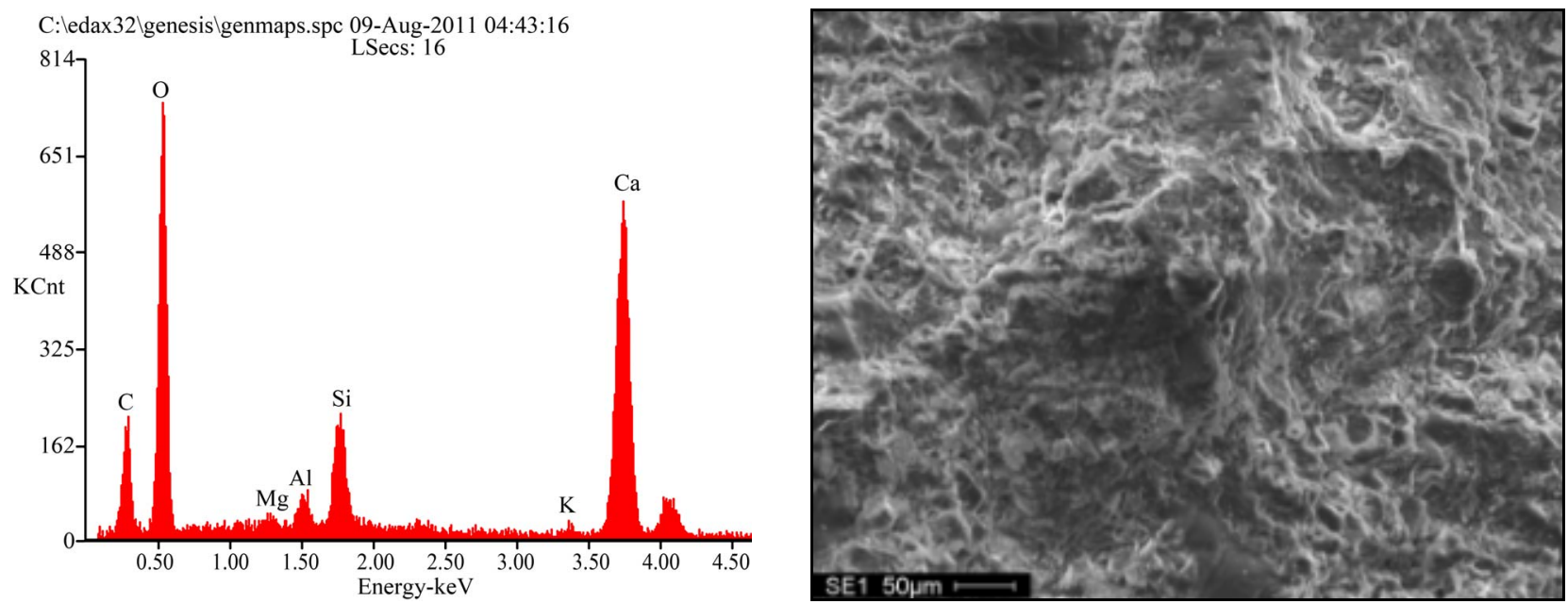

Plate 7. EDS/SEM morphology of the recycled polyethylene reinforced with $25 \mathrm{vol} \%, 400 \mu \mathrm{m}$ size. 
The microstructure reveals that there are small discontinuities and a reasonably uniform distribution of particles and the RLDPE. The particles phase is shown as white phase, while the resin phase is dark. The kernel shell particles are embedded within the amorphous matrix composed of randomly distributed in the matrix planar boundaries. The surface of the agro-waste particles is fairly smooth indicating that the compatibility between particles and the RLDPE was not so good. It can be seen that the agro-waste particles are not detached from the RLDPE surface as the volume fraction of kernel shell particles increased in the RLDPE, from the microstructure it was observed the smallest particles size has good interfacial bonding them the biggest particle size.

The particle size of the reinforced (palm kernel shell particles) has significant effect on the strength, hardness, and impact energy of the composite. From Figure 1, it can be seen that the tensile strength of the composite increases upto a maximum of 5 vol\% of palm kernel shell particles within the matrix of the recycled polyethylene. The tensile strength of composites with $150 \mu \mathrm{m}$ size palm kernel shell particles showed higher value, this is because of increasing in the surface area. This may also account for the good distribution and dispersion of the palm kernel shell particles in the RLDPE matrix resulting in strongparticles-RLDPE matrix interaction. This good particles dispersion will improve the particles-RLDPE matrix interaction and consequently increases the ability of the particles to restrain gross deformation of the RLDPE matrix. Nevertheless the tensile strength obtain in this study remained within acceptable levels for car interiors [8-10].

As expected, the yield strength varies directly with the tensile strength of the samples (See Figure 2). The yield strength slightly decreased as the vol\% of palm kernel shell particles increased in the RLDPE matrix.

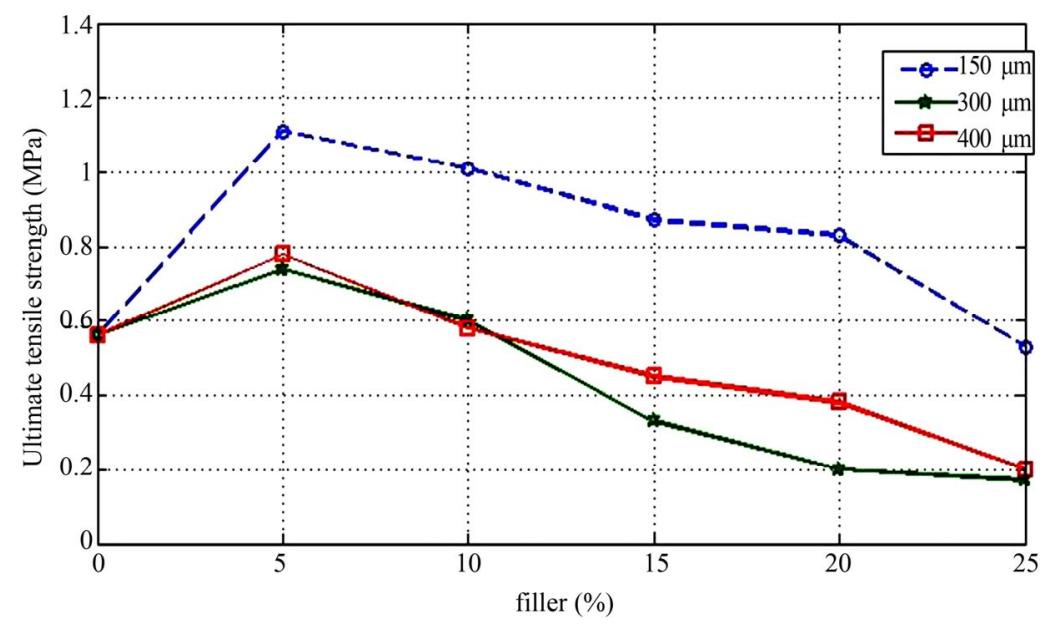

Figure 1. Effect of filler addition on the tensile strength of particulate palm kernel reinforced polyethylene composite.

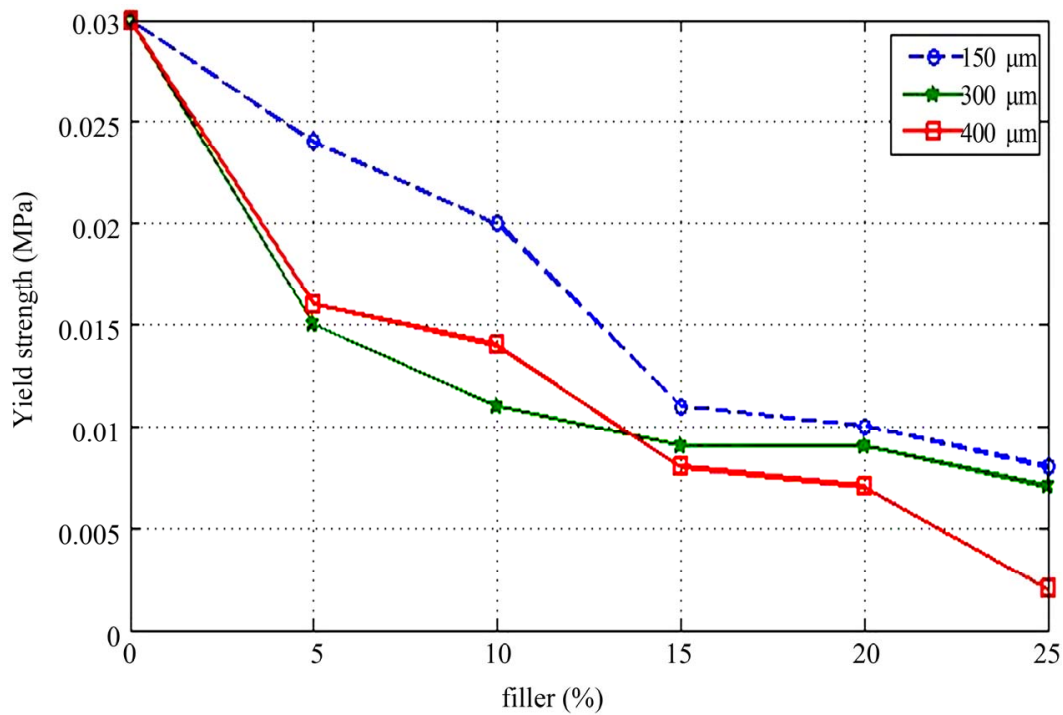

Figure 2. Effect of filler addition on the yield strength of particulate palm kernel reinforced polyethylene composite. 
From Figure 3, it can be seen that the hardness of the composite increases with increase in the kernel shell particles content within the matrix of the composite. This is due to increase in the percentage of the hard and brittle phase of the ceramics body in the polymer matrix. In comparison with the unreinforced RLDPE matrix, a substantial improvement in hardness values was obtained in the reinforced polymer matrix. This is in line with the earlier researches of [10].

The sample with palm kernel shell particles having the smallest particle size shows the highest hardness. A maximum hardness value of $15.4 \mathrm{HRB}$ was obtained for the sample with $25 \mathrm{vol} \%$ at $150 \mu \mathrm{m}$ particle size.

From Figure 4, the impact energy of the composite decreases with an increase in kernel shell particles content within the matrix of the recycled polyethylene composite. The sample with $25 \mathrm{vol} \%$ at $400 \mu \mathrm{m}$ particle size has the lowest impact energy. High strain rates or impact loads may be expected in many engineering applications of polymer composite materials. The suitability of a polymer composite for such applications should therefore be determined not only by usual design parameters, but by its impact or energy absorbing. These results are in agreement with the work of other researchers [8-10].

The rate of water absorption of the composite over a period of 168 hours at an interval of 24 hours increased with increased in kernel shell particles content in the composite. This may be due to imperfect interfacial bonding between the palm kernel shell particle and recycled polyethylene matrix. Also the water absorption is due to the hydrophilic nature of the palm kernel shell (See Figure 5). The swelling that occurs during the water absorption is the sum of two components, namely, swelling by hygroscopic particles and the release of compression stresses imparted to the composites during the pressing of mat in the hot press. The release of compression stresses, known as spring back, is not recovered when the composites is in a dry state.

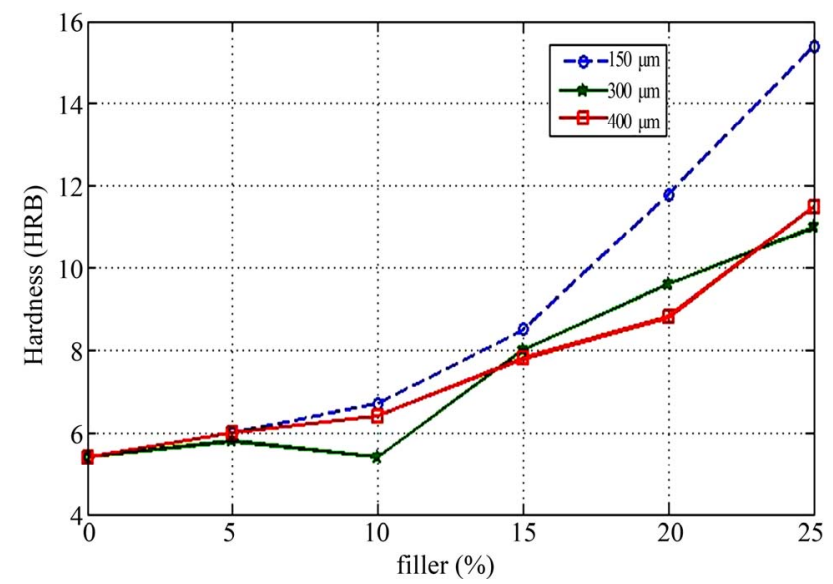

Figure 3. Effect of filler addition on the hardness of particulate palm kernel reinforced polyethylene composite.

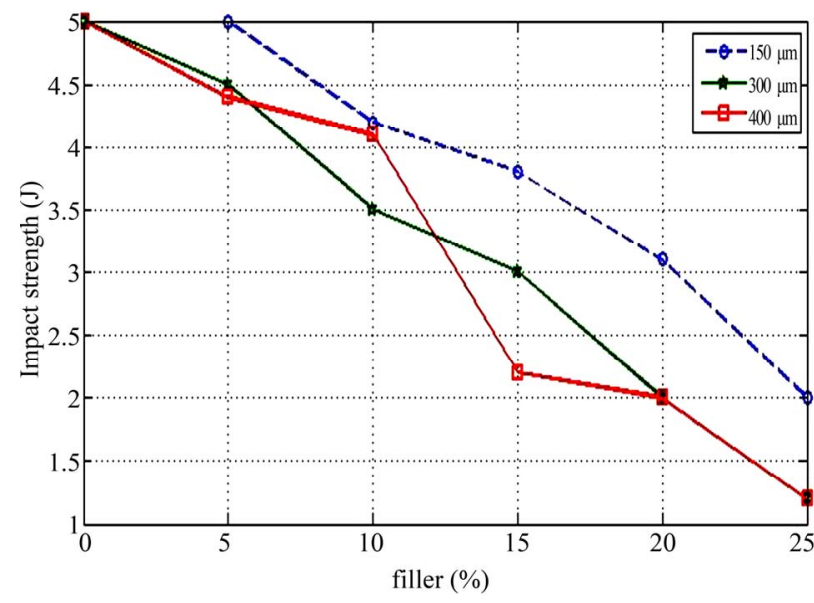

Figure 4. Effect of filler addition on the impact strength of particulate palm kernel reinforced polyethylene composite.

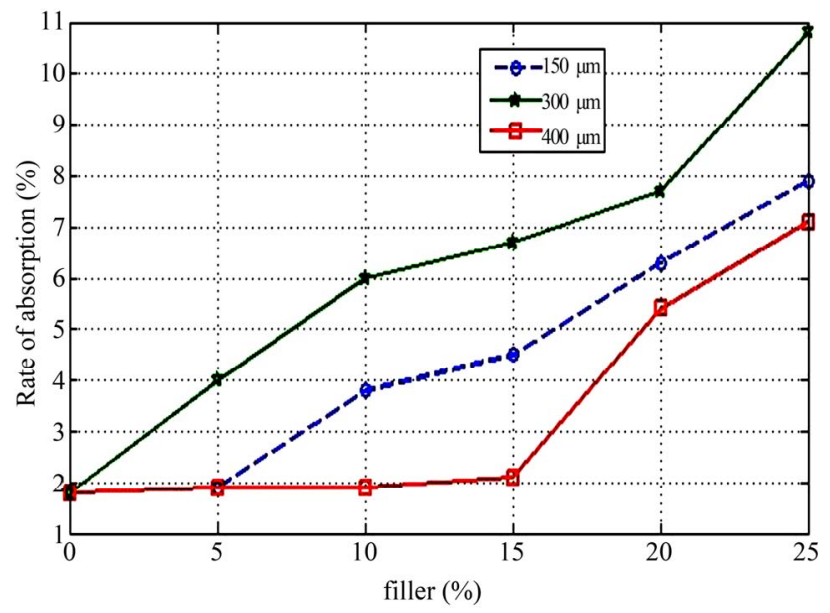

Figure 5. Effect of filler addition on the rate of absorption of particulate palm kernel reinforced polyethylene composite.

\section{Conclusions}

From the result of the investigations and discussion, the following conclusion has been made.

1) This work successfully shows that the fabrication of RLDPE and the palm kernel shell particles composite by compounding and compression moulding is feasible.

2) The uniform distribution of palm kernel shell particle in the microstructure of the composite is the major factor responsible for the increase in strength.

3) Palm kernel shell improves the hardness property of the recycled polyethylene matrix composite.

4) The tensile strength increased up to an optimum of 5 vol\% and the composite produced with $150 \mu$ m particle size has the best properties of the entire grade. Hence this grade can be use for interior applications such as car seat, dash board, and car interior for decorative purposes or other interior parts of automobile where high strength is not considered a critical requirement. 


\section{REFERENCES}

[1] U. Johnson, H. Mahmud and Z. Mohd, "Enhancement and Prediction of Modulus of Elasticity of Palm Kernel Shell Concrete,” Materials and Design Journal, Vol. 32, No. 4, 2010, pp. 2143-2148.

[2] H. Larbig, H. Scherzer, B. Dahlke and R. Poltrock, "Natural Fiber Reinforced Foams Based on Renewable Resources for Automotive Interior Applications,” Journal of Cellular Plastics, Vol. 34, No. 4, 1998, pp. 361-379.

[3] D. Rozman, A. Zainal and S. Umaru, "Natural Fibers, Biopolymers, and Biocomposites: Oil Palm Fiber-Thermoplastics Composites,” CRC Press, Boca Raton, 2005.

[4] P. Wambua, U. Ivens and I. Verpoest, "Natural Fibers: Can They Replace Glass in Fiber-Reinforced Plastics?” Composites Science and Technology, Vol. 63, No. 9, 2003, pp. 1259-1264. doi:10.1016/S0266-3538(03)00096-4

[5] P. Wambua, B. Vangrimde, S. Lomov and I. Verpoest, "The Response of Natural Fiber Composites to Ballistic Impact by Fragment Simulating Projectiles,” Composite Structures, Vol. 77, No. 2, 2007, pp. 232-240. doi:10.1016/j.compstruct.2005.07.006

[6] R. Kozlowski and M. Helwig, "Lignocellulosic Polymer Composite,” In: P. N. Prasad, Ed., Science and Technology of Polymers and Advanced Materials, Plenum Press, New York, 1998, pp. 679-698.

[7] M. M. Davoodi, "Conceptual Design of a Polymer Composite Automotive Bumper Energy Absorber,” Materials \& Design, Vol. 29, No. 7, 2008, pp. 1447-1452. doi:10.1016/j.matdes.2007.07.011

[8] D. J. Andrea and W. R. Brown, "Material Selection Processes in Automotive Industry," Michigan Transportation Research Institute, Ann Arbor, 1993.

[9] E. W. Godwin and F. L. Matthews, "Review of the Strength of Joints in Fibre-Reinforced Plastics: Part 1 Mechanically Fastened Joints," Composites, Vol. 11, No. 3, 1980, pp. 155-160. doi:10.1016/0010-4361(80)90008-7

[10] S. Jevanthi and J. JanciRani, "Improving Mechanical Properties by Hybrid Long Fiber Reinforced Composite for Front Beam of Automotive," European Journal of Scientific Research, Vol. 60, No. 2, 2011, pp. 195-199. 